\title{
HIGHER EDUCATION AND SOCIAL SCIENCES
}

\section{N. Pervushina ${ }^{1^{*}}$, L. V.Kochetova ${ }^{2}$, I. M. Bocharova3, N.M.Morozova ${ }^{4}$, E. A. Timofeeva $^{5}$}

\author{
${ }^{1}$ Ph.D, State University of Justice, Central branch, Voronezh, Russian Federation, email \\ veravalen47@yandex.ru \\ ${ }^{2} \mathrm{Ph} . \mathrm{D}$, State University of Justice, Central branch, Voronezh, Russian Federation, email \\ koch90@rambler.ru \\ ${ }^{3} \mathrm{Ph} . \mathrm{D}$, State Technical University, Voronezh, Russian Federation, email \\ irinabocharova58@gmail.ru \\ ${ }^{4} \mathrm{Ph} . \mathrm{D}$, Voronezh, Voronezh Institute of the Ministry of internal Affairs, Voronezh, Russian \\ Federation, email nadezhdamorozova11@gmail.com \\ ${ }^{5} \mathrm{Ph} . \mathrm{D}$, Research Institute of the Federal penitentiary service of Russia, Moscow, Russian \\ Federation, email anna0474@mail.ru \\ ${ }^{*}$ Corresponding Author
}

\begin{abstract}
The paper is dealt with the analysis of the importance of teaching of social sciences (social philosophy, sociology, political science, ethics, etc.), their role in the formation of not only a highly qualified specialist who meets the requirements of modern civilization with its new technologies, but also the reproduction of a personality of moral and spiritual potential. Modern civilization is facing with new challenges on a global scale that were previously unknown - the global environmental crisis, climate change, global social problems-poverty, terrorism, etc. Teaching in higher education should be based on the synergistic approach, focusing on the means of ensuring of students' self-education, self-reflection, and their desire for continuous self-improvement in order to adequately respond to the challenges of modern civilization. This is possible within the framework of subject-subject relations, in which the teacher provokes interest not only in the knowledge of the surrounding social world, but also in self-reflection. The ethical understanding of knowledge, focused on the knowledge of the external world, is constructed. The synergetic approach includes subject-subject relations which are the process of co-creation of the teacher and the student. And in this case, a large place belongs to the social sciences. The paper reflects the authors' long-term experience in teaching social sciences at the University and the role of these sciences in shaping of the student's personality.
\end{abstract}

Keywords pedagogical activity, global problems of modern civilization, the synergetic approach, selfrealization of personality, educational process as co-creation of the teacher and the student, education and social sciences

\section{INTRODUCTION}

The very concept of "learning" is ambiguous. It covers such an important part of human social existence that 
the definition of this concept is being discussed not only by teachers, but also by psychologists, sociologists, and philosophers. As a rule, learning is a two-way process carried out by the teacher (teaching) and the student (learning). In teaching, these two sides are always clear: teaching and learning. Just as there is no teacher without a student, there is no student without a teacher.

Teaching, as a teacher's activity, consists in presenting the material and working on the application of knowledge, verification of knowledge acquisition, skills, and abilities of students.

Teaching, as a conscious activity of students, is realized in their perception of certain objects and processes, comprehension of studied facts, phenomena and connections between them, generalization of perceived facts, consolidation and application of knowledge (Danilov 2005, 115).

The task of the teacher is to help students in carrying out this activity by making it to be the joint one. Therefore, the subject of such activity is a collective (social) one. The subjects participating in it are a kind of coordinated system which is characterized by specific behavior associated with individual characteristics, but with the same goal. There is no doubt that learning is a phenomenon related to social reality. Today, the social environment, surrounding a person, is constantly becoming more complex, and at the present time, humanity is facing with global problems (environmental and social in its nature). In order to respond adequately to the challenges of modern civilization, it is necessary to change the paradigms of the educational process, change the philosophy of education, which would lead to the formation of a personality who would be able to solve the tasks facing her/him at the present time. The purpose of the paper is to analyze a different paradigm of education, the essence of which is the synergetic approach. Understanding of this approach and necessity implementation is analyzed in the publication. The authors use the systematic and comparative approaches, articulate the synergistic approach as well.

\section{EDUCATION AS AN ELEMENT IN THE SYSTEM OF EDUCATIONAL ACTIVITIES}

Education is a system of interaction. The interaction involves not only the person himself/herself, but also the products of his/her activities, in particular scientific knowledge, which acts as a means of his/her further activities, the main function of which is to ensure the preservation and continuous development of human society (Kagan 1974,48). This interaction is the result of the absorption of accumulated human experience, passed from generation to generation. As experience becomes a public property, the learning in which this experience is transmitted, is also determined by social activities. Thus, in the course of social development, learning becomes a specific type of social activity, and turns into a means of transmitting social experience.

In the educational process, there is a transfer of the social experience, based on a specific activity. At the same time general principles, norms, models, and schemes of future professional activity are transmitted in the educational process.

Getting a professional education begins with the process of adaptation of the future specialist to the system of requirements, principles, norms, patterns of behavior, situations, factors, lifestyle in specialized conditions requiring " psychological regulation of purposeful human behavior and mental image-a subjective conceptual model of activity " (Trofimova 2006, 39).

Professional image- conceptual model of the future specialist's activity is based on formed social experience in a particular professional field. Taught image-conceptual model will be implemented in the future in real professional activities.

Students in higher educational institutions should be prepared for future professional activities.

The legal profession, for example, requires serious theoretical and practical training, so the educational process includes theoretical disciplines in social sciences and humanities (social philosophy, philosophy, sociology, political science, professional ethics, etc.) The training program also includes theoretical courses in law and special disciplines, aimed at developing practical professional skills and abilities and related to legal activities. But, first of all, we pay attention to the importance of courses in social sciences, forming the necessary theoretical base for students to develop intelligence; the ability to analyze, generalize, reflect; and value attitude to life, society, global problems of our time. Analysis of the learning process at the social level requires its regarding in dialectical unity with the process of education. A person-oriented approach to the learning is a characteristic feature of modern education process. It is known that the goal of a personcentered education is not only the formation of professional skills, but also the training of a spiritually rich person, creatively and emotionally developed.

As for the educational process, a person-oriented education is associated with the training of such qualities that are of a value-oriented and normative-evaluative nature: a sense of duty, civil responsibility, reliability, 


\section{fairness.}

The life position, values and guidelines of the future specialist, instilled in him/her in the course of learning, should characterize him/her as a mature personality, ready to perform their professional tasks.

Not by chance the transformation of morality is one of the challenges in the modern world. The loss of moral foundations, moral values, and the predominance of mass culture are characteristic features of the twentyfirst century. This phenomenon has an impact on education as well. This process leads to the "value equivalence of professionalism and amateurism" which negatively affects the prestige of education (Nalivaiko 2010,69).

Education and training, as elements of a single educational process, form the basis of modern education. "There is always a need to transfer social experience which is expressed in certain skills, through special activities of education and training" (Poltoratsky 1972, 78-79). The educational process in higher education institutions follows these principles of learning. This is evidenced by a large block of social disciplines and humanities studied at universities, namely: "sociology and political science", "philosophy", "logic", "professional ethics", "rhetoric", "culture of speech". The teaching of the above-mentioned disciplines is aimed at the successful implementation of educational activities as a system.

\section{SYSTEM APPROACH IN THE PROCESS OF TEACHING SOCIAL SCIENCES}

The study of methodological aspects of teaching courses in social sciences and humanities in the process of training of specialists in higher education institutions has always aroused interest at the scientific pedagogical environment. This interest is due to the specifics of the social sciences and humanities itself and the peculiarities of its study. Originality of social sciences and humanities is also manifested in the special status of social knowledge, forming a student as a personality. The social knowledge teaches understanding of different conceptions, ideas; develops the ability to analyze social phenomena, correctly evaluate them; competently expresses their thoughts; develops value orientations, allowing to have a clear civil position based on specific knowledge (facts, examples).

The distinction between humanities and natural knowledge is considered to be artificial by many scientists. Thus, according to professor E. A. Lebedev, "there is no sharp line of demarcation between modern natural science, social sciences and humanities (Lebedev 2006,6). Of course, there is a certain difference between modern natural science, social sciences and humanities, but the thesis that they develop common social and value grounds is no doubt about it.

Taking into consideration, the commonality of modern natural science, social sciences and humanities, we can also talk about common methods of its study. And in this case the systematic approach can be considered as a general method.

The system approach, regarding as a direction of methodology of scientific knowledge and social practice, considers objects as systems and focuses on revealing the integrity of the object, on identifying various types of connections in it and integrating them into a single theoretical picture.

Scientists and teachers have been talking for many years about using the system approach as the most effective method of studying social sciences and humanities.

A special place in the methodology of teaching humanities is given to the so-called "construction of problem situations, problematic issues and tasks". For a long time it was considered that a lesson which did not solve problematic issues or situations was not productive. But teaching experience shows that the requirements of this research method are not always feasible. They cannot be applied where the material "resists" to it, as a result, problematic issues and tasks sometimes have only the appearance of problematic. No wonder, that one of the main methodological rules of F.P. Buslaev-a scientist and teacher-is formulated as follows: "... all historical and positive ("normative") cannot be taught heuristically, because a student will in no way arrive by his/her own reasoning at a fact that is subject only to memory " (Buslaev 2019, part I, 12). This rule is not outdated and is included in the golden fund of the methodology of humanities. Indeed, it is not necessary to spend time on "research" by students of what they just need to remember, just as well as on their own deduction of laws or rules, if we are talking about complex issues for which the students have no knowledge or experience. So, many tasks, for example, on rhetoric are of a reproductive nature, and require painstaking systematic work to develop certain skills.

As you know, the process of cognition, which is a part of human life, can be both reproductive and creative. So, there are certain problems that need to be resolved: what are the features of creative activity in the acquisition of the humanities and social sciences and what is the specificity of the creative principle. 
It is extremely difficult to describe the features of creative activity, since "there is no algorithm for creative procedures, no system of actions that can be presented to a student" (Barinova 1994, 61). How it is projected into the social sciences and humanities? The answer to this question will be the more reasonable than the deeper will be carried out the analysis of the content of various courses in order to identify the components in them, determining the different ways of learning, and, consequently, the educational activity of a certain type. It requires systematization and ordering from the point of view of a single conception. However, there are still many unresolved issues. They include the previously mentioned question about the nature of creative activity in the process of mastering the subject. It is possible that creative activity that is motivated in both cases by different motives includes different components, and is organized in different ways, has common characteristics. One of them, according to authors' point of view, is defined in the following statement: "The procedures of creative activity cannot be transferred except by including a person in a feasible activity that requires the manifestation of certain creative features and thus these features are forming" (Paley 1999, 152). And yet it seems appropriate even terminologically (because a strictly defined scientific concept is fixed in terms) to separate the reproductive research method which provides activity in the learning of the basics of science in any subject, and creative, serving its development, the development of additional material.

\section{THE SYNERGETIC APPROACH IS TO THE FUNCIONAL COMPETENCE PARADIGMA OF EDUCATION AND THE CONCEPT OF PERSONALITY}

The competence approach includes the following principles: the ability to solve problems independently in various fields of activity based on the use of social experience. The content of education is a didactically adapted social experience of solving cognitive, worldview, moral, and other problems; creating such an organization of the educational process that would contribute to form conditions for independent decisionmaking in various areas. It was believed that the competence approach (see Zimnaya 1998; . Verbitsky, Larionova 2009; Raven 2002 ; Khutorskoy 2013 ) would allow to form a personality that will become an independent agent of social action. The key competencies should be the result of education fitting into the functional paradigm-to meet the demands of employers, "help to become more successful", to survive in a multi-factor socio-political, market-economic, information and communication-rich space. Updated competence matrices were being created periodically, representing a "hierarchical educational ladder", the ascent on which must necessarily lead to higher educational results. The number of general cultural and professional competencies varies depending on the discipline. Thus, in the basic part of the humanities, social and economic cycle (bachelor's degree), out of 14 general cultural competencies there are in philosophy -3 , in economy -2 , professional ethics -3 , and life safety -4 . In the variable part there is logic3; general cultural competence: Russian language and culture of speech-4, rhetoric -6 . It is believed that the acquisition of general cultural competencies will necessarily lead to "the highest manifestations of human education", the formation of the ability to transform reality.

It was assumed that the graduate (bachelor) would master professional education in the field of professional competencies to be enough functionally literate to form a motivation for continuous perfectionism in the field of professional activity. As a result, the practical orientation of education will increase. But, most importantly, the highest goal and value of professional education is declared to be the formation of a mentality - the "quintessence of culture". The four levels: literacy, education, professional competence, and culture must be correlated with adequate technological methods of teaching. The set of core competencies is not final; it is constantly changing, supplemented, etc.

The main goal of the competence approach proposed that a student should be socially demanded, adequate to typical situations Such a set becomes the subject of a request from employers and other customers, and can be corrected depending on the regional situation.

Thus, the competence approach, as one of the grounds for updating education, according to its authors, was designed to focus on the development of certain individual properties and qualities of personality necessary to society and human being. The concept of "competence" includes the following structural components: cognitive (knowledge), operational and technological (skills), personal (motivation), and behavioral. Therefore, proponents of the competence approach consider it to be broader than the generally accepted triad: "knowledge, skills, and abilities".

The strategy of modernization of education in the structure of key competences focuses on the importance of playing roles of citizen, consumer in the sphere of civil-social activities; in the sphere of socio-labor orientation (labor market), and self-assessment of their professional capabilities; in the household, including aspects of health, family, etc. 
It is obvious that the sociological basis of the competence approach is the role conception of the individual in terms of which a personality is considered to be a bearer of certain social statuses and roles, duties and rights meeting normative requirements of the social system and social order.

It is known that the founders of the role conception of personality were Cooley, Mead, Parsons, and others, focusing on the socio-typical manifestations of personality in recurring situations. The role conception of the personality points toward the relationship between the individual and society, the process of socialization. Therefore, the concepts of "social role" and "social status", "role expectations", "role conflict", " valuenormative standards (norms, rules, regulations)" (see Parsons 1998 ) are the main semantic units in the construction of the relationship between the individual and society. T. Parsons, combining behavioral (theory of social action) and systemic approaches, identified the main analytical units of connecting the individual and society - culture, social system, personality, behavioral organism, with the main role given to culture (see Parsons 2000). Value-normative standards are primary in culture. The assimilation and transmission through social institutions-family and education-of cultural patterns is necessary for adaptation, achievement of goals, integration and preservation of the social system. Institutionalization is impossible without integrating standardized expectations with various forms of social control and sanctions that encourage a person to engage in certain behaviors.

The role conception of personality is unthinkable outside the framework of the functional paradigm, the main attitude of which is aimed at describing the structural and functional conditions for maintaining the status quo of the social system. It is possible in the case of meeting the social needs of actors, an adequate motivated action of individuals in the social system and the transmission of cultural symbols. In functional paradigm each subsystem has its own units. For the individual-these are needs-attitudes; for the social systemstatuses-roles; for culture - value orientations. It should be noted that the functional theory of T. Parsons was constructed by analogy with organic and economic theories. In particular, the arguments of economic theory are associated with the symbolic, generalizing, communicative and controlling functions of money, and are transferred to mental and social processes. The preservation of the social system is achieved through the internalization of social prescriptions, which are manifested in conformist behavior; there is an identification of personality and function.

It is understandable. The competence-functional model leaves little room for understanding the rich evaluative content of the human personality. A person differs from an individual subject in that he/she does not submit to his/her own inclination, circumstances, or external pressure. The Personality has principles that must be observed under all conditions, even when they are severely punished. Those who have principles are capable of independent goal-setting. It is only on the basis of independence the real expediency of action, a sustainable life strategy is possible. It requires a rich spiritual and moral potential of personality that goes beyond the general cultural competence, designated as obligatory by the Federal State Educational Standard.

The competence-functional model is concentrated on one-dimensionality and exclusively economic dimension of a person. As a result, the personality of teacher at school, at University disappears, as well the personality of student. Within the framework of the competence -functional model, the teaching staff turns into bearers of templates, patterns and stereotypes, an obligatory set of competencies. Thus, the teacher must have subject, pedagogical, technological, and managerial competencies. Educational and methodological plans-complexes require special mention. They turn into multi-volume "essays" (no one needs) with a detailed description of every minute of the lesson to suggest organizing, controlling, testing students (it is not by chance that the use of unified state exam becomes the fundamental criterion for testing knowledge, and training for it is the main goal of the educational process at school). The passion for the competence tables and their constantly changing set is off the scale! The educational space functions not only as a mechanism for training and education, but also as a place of supervision, hierarchy, and rewards. It is like of the eighteenth century, the period of the early bourgeois era, in which a person was placed in an economy of "industrial type", had utility and trade value (Foucault 1999, 81), and at this time the "general theory of drill" was produced. The creation of tables, serving at the same time as "both a technique of power and a procedure of knowledge" (Foucault 1999, 217), was intended to produce "mechanized individuals conforming to the general norms of industrial society" (Foucault 1999, 354).

The main task, and it is not hidden, of the competence-functional model is to fulfill the social order of the market-type economy: the formation of homo economicus, a successful, demanded, prosperous person in contrast to the loser, downshifter. "The economic component is clearly traced" (Zharov 2015, 23-24) of social order, and in terms of value orientations we can see the attitude to consumption. As a result, a consumer attitude to life is being formed, the attitude to a private momentary success, rejection of state and public 
interests. Therefore, the stated competencies for general cultural development within the framework of the competence-functional approach don't work. The "standard at the exit" is clearly defined-the consumer, the "one-dimensional person" of mass consumption society, ready to do anything for material success. There is a model of one-dimensional thinking and behavior, the same type of discourse and action, brilliantly analyzed by $\mathrm{G}$. Marcuse (Marcuse, 2009). Meanwhile, the implementation of the fourth industrial revolution of Big Data and mitigation of its social consequences requires a whole person, a creative, extraordinary personality, for whom public interests, creative impulse, but not short-term benefits and narrow-minded preferences are the main ones. The consumer is not suitable for this role.

Of course, any training is based on a triad-knowledge, skills, abilities (call it a competence-based approach or another, the essence of this does not change); it is also necessary in modern economic conditions, a utilitarian and pragmatic approach, proclaimed as the defining one in the Russian competence-functional paradigm. But it should be noted that building on this approach, especially modernizing education, is a tribute to a bygone era. It does not meet the needs of a post-industrial, information society, in which not everything can be measured within the framework of an economic table and map of competencies, especially human reproduction.

Many researchers note the limitations of the competence approach, (see Arshinov 1997; Beskova 1993; Evin 2004; Kapitsa, Kurdyumov, Malinetsky 2001) suggest a synergetic approach actualizing selforganization as the basis of evolution. Since pedagogy is an open system, the synergetic approach in pedagogy should focus on the means of ensuring of self-education and the desire for constant selfimprovement. It is possible within the framework of subject-subject relations, in terms of which teacher provokes interest not only in the knowledge of the surrounding world, but also in self-reflection to emphasize personal significance. Subject-subject relations are a process of co-creation between teacher and student. In this context, imagination and creativity are fully included and developed, contributing to the development of the personal beginning, provoking a student to self-regulation and self-education. Personality is a continuous individual decision. Having separated from the world, the personality establishes certain relations in it in the form of feedback. The external world is being transformed, assimilated by the individual. The personality reacts to circumstances in his/her way and responds to them with actions expressing the meaning involved in the individual's action. Personality is a socio-historical phenomenon, a set of social qualities of a human being relying on such deep-psychological mechanisms as conscious will, self-awareness, self-control, and the ability to self-improvement.

The synergetic approach includes a great humanistic potential, regarding the student as a free person. The synergetic approach (its base is the complimentarily of competing processes) is, according to researchers, (see Mukushev 2008; Nazarova ., Shapovalenko 2001) an effective means of solving issues of modern education. There is a great human potential of synergy for the development of personality, the formation of his/her attitudes not only to consumption, but assimilation of general cultural values. The use of a synergetic approach is explained by the challenge of the future state of society and education (Mukushev 2008, 112). It requires the teachers to be persons constantly focused on improving their qualification level and spiritual potential.

The competence approach is aimed at the function of adaptation in society, so knowledge is necessary only for successful career growth. Creative exploration, independent interpretation of the text, etc is not obligatory. The absorption of standards for the solution of standard tasks and finding the answers to the tests is enough. The competence approach does not go beyond subject-object relations.

\section{CONCLUSION}

To overcome the competence-functional approach in the education system is necessary: 1) to indicate the priority spheres of education and culture in society; 2) to make education non-commercial; 3) to improve the social status of teachers, because education requires enthusiastic and ascetic. The state in which the work of a teacher is prestigious and highly paid becomes competitive (Bismarck correctly noted that teachers would win the war). It is known that the mathematical school in the USSR, based on the achievements of the Russian mathematical school of the X1X century, was one of the leading in the world. It was thanks to the development of mathematics that breakthroughs in the economy were made (industry, space exploration, nuclear shield, etc.). It became possible thanks to the Soviet school system and work with gifted children (math clubs, Olympiads, physics and mathematics schools). The work of clubs and training in specialized schools was supported by enthusiasts, scientists, and postgraduates. In addition, it is necessary to implement the Federal conception of education, let's not be afraid of this word - a comprehensively, harmoniously developed personality, because only such a personality can make a breakthrough in modern technologies, respond to the challenges of modern civilization. The relevance of the integral conception of 
Proceedings of SOCIOINT 2020- 7th International Conference on Education and Education of Social Sciences, 15-17 June 2020

education is recognized in the national pedagogical science (see Zimnaya, Bodenko, Morozova 1998).

\section{REFERENCE LIST}

1. Arshinov, V. I., 1997. Cognitive Strategies of Synergetics / / Ontology and Epistemology of Synergetics, Moscow: IFRAN.

2. Barinova, E. A., 1994. Methodology of the Russian Language, Moscow: Nauka.

3. Buslaev, F. I., 2019. About Teaching of the Russian Language. Part 1, Moscow: Yurait ABS (the website).

4. Danilov, M. A., 2005. Didactics, Moscow: Nauka.

5. Evin, I. A., 2004. Synergetics of Art, Moscow: Editorial URSS.

6. Foucault, M., 1999. Discipline and Punish. The Birth of the Prison, Moscow: "Ad Marginem".

7. Kagan, M. S., 1974. Human Activity, Moscow: Nauka .

8. Kapitsa, S. P., Kurdyumov, S. P., Malinetsky, G. G., 2001.Synergetics and Forecasts of the Future, Moscow: Editorial URSS.

9. Kochetkov, V. M., 2014. "Innovations and Pseudo-innovations in Higher Education", Higher Education in Russia, 3: 41-46.

10.Khutorskoy, A. V., 2013. Competence Approach in Training, Moscow: "Eidos".

11.Latov, Yu. V., 2015. "Informal" Rules of the Game "in the Educational System: Educational Simulation, Simulacra and Brokers of Knowledge ", Social Sciences and Modernity, 2: 31-41.

12. Marcuse, G, 2009. One-dimensional Man, Moscow: AST.

13. Mukushev, B. A., 2008. "Synergetics in the Education System", Education and Science, 3(51):.105-122.;

14.Nalivaiko, N. V., Panarin V. I., Parshikov, V. I., 2010. Global and Regional Trends in the Development of Domestic Education (socio-philosophical analysis) (ed. V. V. Tselishchev), Novosibirsk: ISO RAS.

15.Nazarova, T. S., Shapovalenko, V. S., 2001. "Synergetic Syndrome in Pedagogy", Pedagogy, 9: 25-33.

16.. Paley, I. R., 1999. Essays on the Methodology of the Russian Language, Moscow: Enlightenment.

17.Parsons, T., 1998. System of Modern Societies, Moscow: Aspect Press.

18.Parsons, T., 2000. On the Structure of Social Action, Moscow: Academic Project.

19.Poltoratsky, A. F., 1972.Sign and Activity, Moscow: Nauka.

20.Raven, J., 2002. Competence in Modern Society: Its Identification, Development and Release, Moscow: Kogito-center.

21. Trofimova, N. M., 2006. Formation of Moral and Legal Consciousness of Youth, Voronezh: Voronezh Institute of the Ministry of Internal Affairs of Russia.

22. Verbitsky, A. A., Larionova, O. G., 2009. Personal and Competence Approaches in Education. Problems of Integration, Moscow: Logos.

23.Zimnaya, I. A., Bodenko, B. N., Morozova, N. A., 1998. Education - the Problem of Modern Education in Russia, Moscow: Ministry of General and Special Education of the Russian Federation.

24. Zimnaya , I. A., 2004. The Key Competencies as a Result-oriented Basis of the Competence Approach in Education, Moscow: Research Center of Problems of Quality of Professional Training.

25.Zharov, S. N., 2015. "Education and the Image of the Future", journal Vestnik of Voronezh State University. Philosophy, 4: 21-26. 